\title{
0 caipira e o travesti. 0 programa gestual de um ator-autor: Matheus Nachtergaele
}

////////////////// Pedro Maciel Guimarães ${ }^{1}$ da Escola de Comunicações e Artes da Universidade de São Paulo e bolsista da Fapesp (Fundação de Amparo à Pesquisa do Estado de São Paulo).E-mail: pedromacielguimaraes@gmail.com 


\section{Resumo}

As performances dos atores de cinema e suas relações com os diretores são objetos constantes de reflexões sociológicas e históricas, mas elas ainda carecem de teorias capazes de dar conta da importância estética em torno da encarnação de um personagem dentro de um filme. A teoria do ator-autor, proposta por Patrick McGilligan, analisa o ator como objeto estético, como forma fílmica, na mesma medida de outros componentes da mise-en-scène (luz, enquadramentos, montagem). São atores-autores aqueles intérpretes capazes de estabelecer um sistema de interpretação, uma "obra", e influenciar a concepção de um personagem, de um plano, de uma sequência ou de um filme inteiro. Matheus Nachtergaele é um ator-autor, e seu estatuto é representativo da evolução histórica do paradigma de atores brasileiros.

\section{Palavras-chave}

atores de cinema, ator-autor, estética do cinema

\section{Abstract}

The performances of the movie actors and its relations with the directors have always been the target of historical and sociological reflections but they still lack theories capable of giving account of aesthetic importance around the incarnation of a character in a movie. The theory of actor as auteur, proposed by Patrick McGilligan, analyzes the actor as an aesthetic object, as a filmic form, to the same extent as other components of the mise en scène (light, frameworks, montage). Actors-auteurs are those interpreters able to establish a system of interpretation, a "work", and influence the conception of a character, a plan, a sequence or an entire movie. Matheus Nachtergaele is an actor-author and its status is representative of the historical evolution of Brazilian actors paradigm.

\section{Keywords}

movie actors, actor-auteur, aesthetics 


\section{Propostas de reflexão sobre os atores de cinema}

A teoria do cinema nos ensinou a menosprezar o trabalho do ator ou a ver no trabalho de encarnação do intérprete de cinema apenas dimensões sociológicas e práticas: as análises em torno do star system e dos cultural studies nos deram uma série de paradigmas de reflexão sobre o valor mercadológico dos astros e sobre a representação das minorias, os chamados gender studies anglo-saxões.

No campo da sociologia, Edgar Morin dedica um estudo consistente ao fenômeno das estrelas, intitulado Les stars (publicado em 1957), quando o star system hollywoodiano já havia conhecido seu apogeu, 20 anos antes. Já os teóricos do cinema demoraram algum tempo para realizar verdadeiras análises estéticas sobre os atores. Era traço comum entre os primeiros escritos de teoria do cinema ora um silêncio completo sobre a importância dos atores, ora um aberto preconceito contra eles, ora uma relativização do aporte deles para a composição global do filme. Boris Kazanski, por exemplo, membro do grupo dos formalistas russos dos anos 20, afirmava que o "o intérprete de cinema não goza das mesmas faculdades e talentos que constituem a arte do ator de teatro", propondo o termo "arte da pose" para falar da aparição dos corpos nos filmes e reservando o termo "arte dramática" aos intérpretes teatrais (KAZANSKI, 1996, p. 117). Na mesma época, dentro do cinema de vanguarda europeu, Germaine Dulac, realizadora e teórica, defendia que "dentro de um cinema puro, não ligado à obrigação narrativa da literatura nem à realidade fotográfica, somente há lugar para o ator como motivo plástico, linha ou 
mancha" (apud ALBERA, 1995, p. 37). As opiniões desse tipo se repetem ao longo do século e chegam a contaminar até pensadores de outros meios de representação, como Erwin Panofsky, para quem o personagem de cinema não pode ser considerado um todo unificado devido à sua existência diretamente condicionada pela colagem "pedaço a pedaço" da montagem (PANOFSKY, 1978, p. 58), e Walter Benjamin, que qualifica a interpretação do ator de cinema como um "recomposto a partir de uma série de performances descontínuas", que levam à perda da aura do intérprete (BENJAMIN, 2003, p. 40-43).

Diversas das análises citadas estabelecem uma comparação de atores de cinema com os de teatro, na maioria das vezes valorizando estes em detrimento daqueles. Esse fato explica-se pela importância que sempre tiveram os intérpretes dentro da criação teatral. De fato, a teoria do teatro e os escritos de grandes diretores - dentre eles, Denis Diderot, Constantin Stanislavski, Vsevolod Meyerhold e Bertolt Brecht - forneceram uma série de paradigmas de análise do trabalho do ator como forma. $\mathrm{Na}$ passagem do método stanislavskiano para o cinema americano, Lee Strasberg, um dos nomes mais importantes do "Actors Studio" nova-iorquino, tentou ousar uma aproximação entre a criação do ator teatral e a de seus colegas do cinema.

O pensamento de Lee Strasberg representa o apogeu de uma preocupação que já vinha sendo tratada nos escritos dos diretores de cinema desde os primeiros tempos: a reflexão sobre a prática de uma arte, entremeada de esboços de uma teoria ainda embrionária e, sobretudo, de uma admiração sem limites dos criadores por suas criaturas. De Jean Renoir a Alain Resnais, passando por Josef von Sternberg, Ingmar Bergman, Andrei Tarkovsky, John Cassavetes, Rainer Werner Fassbinder e Wim Wenders, os atores de cinema sempre tiveram seu trabalho vangloriado pelos diretores, além de serem alçados, às vezes, ao estatuto de coautores dos filmes. Não por acaso, esses diretores sempre trabalhavam com os mesmos atores, transportando para o cinema a lógica da trupe teatral. Até mesmo diretores conhecidos por maltratarem seus atores (Alfred Hitchcock, Jean-Luc Godard, Maurice Pialat) ou por fazerem deles 
2. O termo "direção de atores", usado aqui entre aspas, é bastante polêmico e constantemente evitado

por imprimir uma dimensão paternalista ao trabalho do diretor

com os atores. Se os diretores

não dirigem os atores, eles são responsáveis, com exceção de alguns

filmes documentários, experimentais ou baseados na improvisação de gestos, pelo tom de suas interpretações e pelas movimentações do seu corpo em cena. meros modelos para suas composições formais (Robert Bresson, Jean Marie Straub e Danièle Huillet, e Manoel de Oliveira) devem à relação com os intérpretes grande parte do interesse em suas obras. Nesse sentido, a contribuição de Bresson é inestimável, pois, mesmo tratando seus atores como "modelos", ele construiu uma teoria consistente sobre a "direção de atores"2 como elemento fundamental na construção plástica do filme.

Nossa reivindicação é, partindo das bases do pensamento teatral e das reflexões práticas dos diretores, tratar os atores de cinema como os de teatro e usar a prática da arte de interpretar para construir uma teoria. O que se pretende é dedicar análises estéticas às performances dos atores de cinema, descrever e analisar seus gestos, sua postura vocal, seu programa gestual, sua sistemática formal e a temática de suas aparições na tela. Pretende-se, também, pensar o conjunto de seus filmes como uma "obra" e investigar sobre questões práticas e simbólicas do momento da encarnação de um personagem ficcional no que diz respeito às relações entre ator e personagem e entre ator e diretor. Nesse corpo singular, que é o corpo do ator, em que instrumento se confunde com obra, podemse ler traços não somente de momentos de criação do filme mas também das escolhas de mise-en-scène do diretor.

\section{A teoria do ator-autor}

É nessa perspectiva que o teórico e biógrafo de estrelas de Hollywood Patrick McGilligan forjou, em 1975, o conceito de "ator-autor". Para falar das contribuições de James Cagney nos filmes em que ele aparecia unicamente como ator, McGilligan se pôs a investigar de que maneira a simples presença do ator "define a essência dos filmes" (McGILLIGAN, 1975, p. 33), impondo decisões estéticas ao diretor - escolha de certos tipos de plano, de um tipo determinado de personagem - e determinando, de maneira geral, a mise-enscène de um plano, de uma sequência ou até de um filme inteiro. McGilligan analisa também de que maneira Cagney repetia uma série de elementos corporais de encarnação em todos os seus papéis, pouco importando o tipo de personagem, o tom do filme 
ou as preferências pessoais de um diretor. Segundo McGilligan, os trejeitos de Cagney contaminariam até mesmo seus parceiros de cena, pois, seus filmes, apesar de centrados em personagens durões e cruéis, traziam cenas em que "os gângster parecem dançar", seguindo a maneira leve e saltitante que Cagney tinha de emprestar movimento aos seus mafiosos.

McGilligan criou o conceito de ator-autor ("the actor as auteur”), mas não se preocupou em desenvolvê-lo nem em ampliálo a outros objetos de estudo. O único retorno que ele fez à sua reflexão inovadora foi em 2007, quando comparou a experiência do ator Cagney a outros dois atores-autores, Ronald Reagan e Clint Eastwood, numa obra coletiva editada justamente por seus leitores mais assíduos, os membros do Grac (Grupo de Pesquisa sobre Atores de Cinema), ligado à Universidade de Paris 1 e à revista Positif. Nos últimos anos, McGilligan tem se dedicado a escrever sobretudo biografias de astros e diretores de Hollywood (Jack Nicholson, Clint Eastwood, Nicholas Ray, Alfred Hitchcock), deixando para pesquisadores, em sua maioria franceses, a tarefa de atualizar e ampliar seu conceito.

$\mathrm{Na}$ França, os conceitos de McGilligan tiveram sua mais ampla aplicação. Primeiramente, através da obra analítica de Luc Moullet, Politica dos atores, sobre Cary Grant, Gary Cooper, John Wayne e James Stewart, e, mais tarde, através dos estudos do Grac, que tiveram o mérito de atualizar a discussão e ampliar as análises às atrizes (Catherine Deneuve, Audrey Hepburn) e aos intérpretes de outras gerações (Johnny Depp). Essas análises circunscrevem-se, no entanto, a um tipo de cinema bastante codificado (cinema de gênero, atores de comédia, atores de western, atores de filmes policiais) e, sobretudo, propagam-se entre os atores que, de uma maneira ou de outra, são oriundos do star system norte-americano. O conceito de ator-autor carece ainda de uma aplicação mais ampla e sistemática, o que inviabiliza que o consideremos como uma teoria plena. 


\section{$\mathrm{O}$ ator-autor no cinema brasileiro}

A restrição a objetos oriundos do cinema de gêneros e no qual o star system já está amplamente enraizado é só a primeira dificuldade em adaptar o conceito de ator-autor para intérpretes brasileiros. Nosso cinema padece de uma carência de qualificação genérica mais desenvolvida e está só engatinhando no quesito formação de estrelas. Apesar de tentativas históricas marcantes, como os anos 40 e 50, que criaram lendas como Oscarito, Grande Otelo, Mazzaropi e Carmen Miranda, as constantes interrupções da produção e, sobretudo, a definição de um modelo televisivo (para não dizer "Global", ou seja, ligado à Rede Globo de Televisão) de star system impedem que nossos atores de cinema usufruam de uma constância de trabalho e de uma consequente popularidade fora das telas, o que é necessário à formação dos atores-astros no modelo de Hollywood ou do cinema europeu. Não é por acaso que todas essas estrelas do cinema brasileiro evoluíram no meio de um cinema altamente codificado, como a comédia de costumes, a chanchada e os musicais.

A questão da interdependência entre cinema e televisão é ainda mais delicada. Historicamente, os intérpretes nacionais se viram, de uma maneira geral, obrigados a recorrer ao meio televisivo. Isso gerou um modelo singular de compreensão do trabalho do ator, pois o movimento pendular que os atores estabeleceram entre esses dois meios de representação é essencial para compreender não só o sistema de estrelado à brasileira mas também as contaminações recíprocas entre personagens televisivos e personagens cinematográficos.

O que caracterizou essa passagem do cinema para a televisão foi, no entanto, o subemprego. Alguns atores que despontavam em carreiras sólidas no cinema foram, na televisão, relegados a papéis secundários estigmatizados e resumidos aos clichês de um tipo físico. Foi o caso de atores como Grande Otelo e Wilson Grey, que terminaram a carreira com pequenas participações em programas de humor de gosto duvidoso; de Norma Bengel, Odete Lara, Darlene Glória e Ítala Nandi, estrelas incondicionais nos filmes, mas que nunca emplacaram como musas da TV; além de Paulo 
César Pereio, Leonardo Villar, Maurício do Valle, Othon Bastos, Antonio Pitanga, Nelson Xavier, Jardel Filho, Jofre Soares, Ruth de Souza, Nelson Dantas, Maria Gladys, José Dumont, Marcélia Cartaxo e Fernando Eiras. No outro lado da moeda, alguns atores, como Paulo José, Hugo Carvana, Tônia Carrero e José Lewgoy conseguiram na televisão destaque similar ao obtido nas telas. Do mesmo modo, Oscarito, Carmen Santos, Mazzaropi, Carmen Miranda, Paulo Autran, David Cardoso, Leila Diniz, Isabella, Helena Ignez, Guará Rodrigues, Fernando Alves Pinto, Paulo Miklos e Seu Jorge, atores de perfis e momentos diferentes, podem ser considerados exceções, pois são intérpretes que construíram suas carreiras de maneira independente do meio televisivo, em épocas em que a passagem para a televisão era praticamente obrigatória. Numa terceira vertente dessa tipologia dos atores brasileiros baseada nas relações entre cinema e televisão, podem ser colocados aqueles intérpretes que construíram carreiras mistas, como Fernanda Montenegro, Lima Duarte, Yoná Magalhães, Marília Pêra, Tarcísio Meira, Sônia Braga, Fernanda Torres, Marco Nanini, José Wilker, Maitê Proença, Ana Beatriz Nogueira, Glória Pires, Rodrigo Santoro, Mariana Ximenes, Caio Blat e Leandra Leal. São atores que, embora apareçam essencialmente no teatro e na televisão, tiveram performances consistentes e importantes em produções pontuais.

A experiência recente de atores como Selton Mello, Wagner Moura, Milhem Cortaz, Lázaro Ramos, Gero Camilo, Dira Paes, Fabiula Nascimento, Hermila Guedes e Alice Braga, oriundos do cinema e repescados pela televisão, pode, no entanto, significar que o modelo esteja mudando e que a televisão não seja a única fabricante de estrelas - embora ainda seja preciso aparecer nela para se estabelecer definitivamente como uma star. Esses atores são menos reféns das imposições econômicas e estéticas do meio televisivo e podem, geralmente, estabelecer uma abordagem mais autoral e singular em relação à escolha de papéis e às possibilidades de encarnação. É seguramente dessa lista que sairão os futuros atores-autores do cinema brasileiro. 


\section{Matheus Nachtergaele: ator-autor}

Um ator como Matheus Nachtergaele goza de um perfil único dentro do cinema brasileiro, abrindo a possibilidade de ser encarado como ator-autor, embora fuja das regras básicas do star system. Segundo Edgar Morin, para que o ator seja considerado uma estrela, são necessários alguns elementos básicos: que ele evolua num poderoso sistema econômico de criação de produtos audiovisuais; e que haja osmose entre ator e personagem, e não absorção do ator pelo personagem, fazendo o primeiro desaparecer por detrás do segundo (ou seja, em que um não engula o outro). O terceiro critério, polêmico, exclui os chamados atores de composição do estrelato, o que, evidentemente, não pode ser levado a sério se tomarmos o exemplo de Meryl Streep e Robert de Niro, abertamente atores de composição, que se "transformam" nos personagens, mas que não deixam de ser estrelas. A esses critérios, podem-se incluir o valor mercadológico do ator (possibilidade de se fazer garoto-propaganda) e o interesse popular despertado pela vida pessoal dele, o que alimenta revistas especializadas em fofocas de bastidores, indispensável para manter o interesse em torno da estrela de maneira durável. Desses cinco critérios, Nachtergaele obedeceria a apenas um deles, o principal: o de haver osmose, e não absorção total, entre ator e personagem (tentaremos provar isso, apesar de as apreciações, críticas e populares, sobre a qualidade de interpretação do ator estarem ligadas a essa capacidade de "entrar" na pele de um tipo). Com relação aos demais, Nachtergaele estaria completamente excluído do star system: o ator raramente aparece na televisão, que no Brasil é o único "poderoso sistema econômico de criação de produtos audiovisuais", como dito acima, e, quando o faz, é em participações pequenas ou coadjuvantes (Morin diz que, para ser estrela, o ator deve ser sempre principal); sua imagem não "vende" e efetivamente não aparece ligada a produtos; e, finalmente, não se pode ter exemplo de ator mais discreto quanto à sua vida pessoal e fora do interesse da imprensa de celebridades.

Ainda assim, permitimo-nos tecer considerações sobre Matheus Nachtergaele ator-autor, por diversas razões. Nachtergaele, que começou no grupo de teatro Vertigem, em São Paulo, teve carreira 
consolidada no cinema antes de aparecer na televisão. Seu perfil de ator estaria próximo do que Luc Moullet chama de atores convergentes, citando o exemplo de John Wayne, ator que se especializou em personagens de caubóis e cujas composições rodavam sempre em torno "da velhice, da decrepitude e do tempo que passa” (MOULLET, 1993, p. 61). Nachtergaele não tem um tipo único de personagem, mas suas aparições no cinema e na televisão privilegiam tipos bem definidos: o caipira e sua variante do tipo nordestino (os filmes Tapete vermelho e Central do Brasil, a série O auto da Compadecida); o homossexual e sua variante do travesti (a série de TV Hilda Furacão, o filme Amarelo manga) e o líder espiritual (as novelas Cobras e lagartos e Cordel encantado, e a série A muralha). Desses tipos, analisaremos mais em profundidade os dois primeiros. Outra similaridade entre os papéis de Nachtergaele é a assexualidade ou, melhor dizendo, a ausência de parceiras e histórias de amor, o que é, sem dúvida, influenciado pela discrição do ator em manter sua vida pessoal longe do alvo de revistas de fofocas.

Matheus Nachtergaele se enquadra nas análises feitas por Moullet por outro motivo determinante. Ele obedece às chamadas “orientações essenciais ou figuras de encarnação" (MOULLET, 1993, p. 88), que o teórico francês usa para falar da repetição sistemática de motivos físicos, corpóreos ou gestuais realizada pelo ator Cary Grant em suas aparições no cinema, passando por cima da "direção de atores" de um determinado diretor. Essa orientação essencial de Nachtergaele, parte integrante do seu programa gestual, está ligada à constante oscilação entre calma e frenesi que marca suas performances. $\mathrm{O}$ ator tem a capacidade de, dentro de uma mesma sequência, passar do olhar angelical ao diabólico, da representação da inocência à crueldade e à explosão nervosa. No cômputo final, são a histeria e a confusão gestual que acabam reinando como traço comum aos seus personagens, mas elas são constantemente ameaçadas por silêncios, olhares doces e voz terna.

O personagem Cintura Fina, da adaptação televisiva do romance de Roberto Drummond Hilda Furacão (Rede Globo, 2003, direção de Wolf Maya), por exemplo, guarda durante toda 
a minissérie um movimento pendular entre a doçura do amigo e confidente da heroína, vivida por Ana Paula Arósio (é ele quem a nomeia com o epíteto com que passa a ser conhecida na zona boêmia de Belo Horizonte), e o "endiabramento" dos momentos de brigas a navalhadas com a rival de prostituição de Hilda, Maria Tomba-Homem (Rosi Campos). De maneira ordinária, as representações do travesti oscilam entre o pueril e o proibido, entre a inocência (perdida) e a perversidade (encontrada à força pelo exercício da profissão), entre o companheirismo e a ameaça. O personagem Cintura Fina obedece então a essa representação usual do personagem, como lhe impõem as amarras do meio televisivo.

A histeria e a oscilação de sentimentos atingem, também, personagens mais sutilmente representados; no caso, dois tipos populares que fogem da lógica dos travestis: o caipira Quinzinho, do filme Tapete vermelho (Luis Alberto Pereira, 2005), e o nordestino João Grilo, da série de TV e do filme O auto da Compadecida (Rede Globo, Guel Arraes, 1999; versão para cinema em 2000). O primeiro, um inocente agricultor que vai para a cidade grande para ver um filme de Mazzaropi, tem verdadeiras crises de nervos quando se encontra com o demônio, quando vai preso e, sobretudo, quando se acorrenta à pilastra do cinema, exigindo que lhe mostrem um filme do ator brasileiro. O segundo vive a histeria em tempo constante, que é, aliás, a marca da direção de atores da minissérie de TV, que mescla teatro de rua com vocabulário e situações de cordel. Nenhum dos dois personagens tem conotação sexual dúbia, mas a histeria deles está estranhamente próxima à de Cintura Fina e à de um segundo homossexual encarnado por Nachtergaele, o empregado doméstico Dunga, no filme Amarelo manga (Cláudio Assis, 2002). A dupla face comum a tantos tipos vividos por Nachtergaele se aloja sobre um mesmo corpo justamente em Amarelo manga. A confluência de atitude ofensiva, eticamente questionável, com trejeitos quase infantis aparece quando Dunga escreve uma carta à mulher do homem pelo qual ele é apaixonado, denunciando a sua traição. Fazendo olhinhos de donzela e posando de "amiga", Dunga está sentenciando o açougueiro que o obceca a sofrer com a ira da esposa e, ao mesmo tempo, induzindo a sua rival a cometer um crime violento. 
Se o misto de histeria/calmaria é a orientação essencial das encarnações de Nachtergaele, pode-se notar também, em alguns momentos, uma atitude de abandono do personagem, o que deixa curso livre à possibilidade de aparecimento de uma feição própria ao ator. É o caso do sorriso divertido e maroto dado por Nachtergaele nos últimos instantes de alguns planos - quando a narração parece já ter se extinguido, e o corte não tardará -, nos quais o corpo do ator ainda ocupa o centro de um plano. Esse sorriso funciona como uma espécie de preparação do terreno a uma atitude de distanciamento tipicamente brechtiana, como a do personagem Everardo, de Baixio das bestas (Cláudio Assis, 2006), que interpela o espectador ao verbalizar a reflexão do próprio diretor Cláudio Assis de que "o cinema é bom, pois nele se pode fazer o que quiser". Num cinema tão carente de interpretações brechtianas e menos stanislavskianas, Nachtergaele funciona como repositório de prerrogativas que abrem espaço a reflexões críticas do espectador quanto à natureza do meio de representação e quanto ao conteúdo de alguns filmes.

Finalmente, para tentar relativizar a não absorção completa do ator Nachtergaele pelos seus personagens, o que permitiria considerá-lo como ator-autor, escolhemos dois personagens, um de televisão, outro de cinema. Nesses personagens, Nachtergaele evita a imitação perfeita, a busca pela mímesis sem buracos como nos ensina o pensamento de Stanislavski e do cinema americano de uma maneira geral. Essa mímesis cheia de falhas diz respeito à caracterização física de um personagem e à não aproximação total de um corpo-modelo a ser imitado, seja através da composição física (gestos, jeito de andar, roupas, maquiagem), seja através da abstrata (tom de voz, sotaque). O travesti Cintura Fina, por exemplo, não esconde seus traços masculinos; ao contrário, ele os ressalta. Assim, o personagem multiplica os momentos em que mostra as axilas peludas, nunca usa perucas de cabelos compridos, não tenta imitar trejeitos femininos ao se movimentar e não afina a voz. Da mesma maneira, para viver o agricultor Quinzinho, Nachtergaele não busca a imitação perfeita através do sotaque caipira (o que ele, certamente, conseguiria, visto suas interpretações mais "imitadoras", como a do nordestino Chicó, em O auto da Compadecida). Aproveitando a 
veia abertamente paródica de seu personagem, Nachtergaele cria um sotaque inexistente, uma espécie de gauchesco declamado, que acentua sempre a sílaba final das palavras. A maneira de falar do ator parece ainda mais inapropriada quando ele contracena com a atriz Gorete Milagres, ela sim vinda do interior e especializada num personagem único, a roceira Filó.

A grande qualidade de intérprete de Nachtergaele foi determinante para a direção de atores que ele realizou na sua única direção para o cinema, em A festa da menina morta (2008). Usando atores que foram seus colegas em outras produções e que são nomes do novíssimo cinema brasileiro, tais como Juliano Cazarré, Daniel de Oliveira e Dira Paes, Nachtergaele apoiou seu filme na construção de tipos físicos e psicológicos influenciados por sua colaboração com o diretor Cláudio Assis e com o roteirista Hilton Lacerda. Com Assis, Nachtergaele teve dois de seus grandes momentos no cinema, em Amarelo manga e Baixio das bestas. Não por acaso, a construção plástica de algumas sequências e certa crueza na construção de situações e personagens podem também ser lidas como uma influência dos dois profissionais na definição da forma no filme de Nachtergaele.

Os trejeitos do personagem Santinho, vivido por Daniel de Oliveira, não por acaso são imitados da maneira de interpretar de Nachtergaele. Até a orientação constante de oscilação entre calmaria e histeria Nachtergaele transfere para o personagem de Daniel de Oliveira. Santinho é assim um personagem bicéfalo, que se apoia no corpo e na voz de Daniel de Oliveira, mas cujo programa gestual é decalcado do próprio Matheus Nachtergaele, prova da sua capacidade de autoria em determinar não somente seus próprios personagens mas também aqueles que não são interpretados por ele. Nachtergaele inscreve-se, assim, na tradição de diretores como Pedro Almodóvar e Woody Allen, acostumados a moldar o corpo e a voz dos seus atores à imagem de sua persona pública, seja ela de ator (Allen), seja de diretor-estrela (Almodóvar). A festa da menina morta é uma obra que nos faz entender melhor a amplitude de autoria que Nachtergaele impõe aos personagens que cria, mas é, definitivamente, um filme acessório na construção da persona cinematográfica do ator. 


\section{‘Atores-autores' e 'atores diretores'}

A transferência de Nachtergaele ator para Nachtergaele diretor representa uma exceção no panorama audiovisual brasileiro, ao contrário do que ocorre nos cinemas americano e europeu. No Brasil, tal fenômeno verifica-se, mais facilmente, na televisão e no teatro, em que diretores relevantes como Daniel Filho e Dennis Carvalho, da televisão, e Procópio Ferreira, Zé Celso Martinez Corrêa e Antunes Filho, do teatro, foram também atores de prestígio. A teoria do ator-autor no cinema, no entanto, concentra suas reflexões em torno de atores que não são necessariamente autores do roteiro nem diretores. A particularidade dessa teoria é justamente determinar a influência subterrânea da força da persona de um ator na construção plástica e formal de uma obra. Alguns astros que também dirigiram filmes, tais como Robert Redford, Mel Gibson, Kevin Costner ou George Clooney, dificilmente serão privilegiados como objetos de estudo dessa teoria. Da mesma maneira que Gene Kelly, Marlon Brando e Dennis Hopper serão lembrados, antes de tudo, como intérpretes de excelência, e não como diretores importantes. Esses intérpretes são o que poderíamos chamar de "atores que são também (sobretudo, esporadicamente) diretores". Suas prestações como realizadores não justificam que se olhe para os filmes dirigidos por eles em busca de elementos formais e temáticos constantes que os qualifiquem como autores. Em outras palavras, são mais criadores como atores do que como diretores. Outros que levaram carreiras paralelas, como Charles Chaplin, Erich von Stroheim, Nanni Moretti e Clint Eastwood, aparecem como figuras de exceção a essa regra. Eastwood é, aliás, um dos mais importantes atores-autores do cinema mundial, ator de reconhecida persona cinematográfica, capaz de determinar a forma de um filme mesmo quando ele não assina a direção nem o roteiro. McGilligan afirma até mesmo que alguns diretores com os quais Eastwood trabalhou, como James Fargo (Sem medo da morte, 1976), Richard Tuggle (Um agente na corda bamba, 1984) e Buddy Van Horn (Dirty Harry na lista negra, 1988), eram claramente “dublos ou substitutos de Eastwood atrás das câmeras" e que suas carreiras eram "condicionadas à aparição de Eastwood em seus filmes” (McGILLIGAN, 2007, p. 121). 
Os “diretores fantoches", uma espécie de resposta aos diretores que manipulam ditatorialmente o corpo dos atores, apareceram também na carreira de Cagney. Richard Dyer comenta que "os filmes rodados por diretores como Lloyd Bacon, William Keighley e Roy Del Ruth se parecem assustadoramente, e se parecem mais aos filmes que Cagney rodou com outros diretores que aos filmes desses diretores com outras estrelas" (DYER, 1992, p. 103). Patrick McGilligan conta também que, aproveitando da sua fama de mau construída pelos filmes, James Cagney ligava de madrugada para os roteiristas de seus filmes para "sugerir" novas falas ou modificar cenas inteiras. Os roteiristas, subjugados pela força da presença do ator, acatavam as modificações. Embora anedótico, tal fato mostra como um ator é capaz de determinar o filme em que aparece sem necessariamente contar com os meios práticos para definir roteiro e mise-en-scène. Casos como Cagney e Eastwood são extremos e pouco aplicáveis ao cinema brasileiro, justamente pela falta de paradigmas de construção de um star system mais consistente e capaz de se sobrepor às escolhas estéticas de diretores.

Matheus Nachtergaele passou para a direção de longasmetragens ao mesmo tempo que Selton Mello, que já havia realizado antes um curta-metragem, ao contrário de Nachtergaele. Selton Mello se consagrou definitivamente como diretor em $O$ palhaço (2011), inesperado sucesso de público e crítica, dois anos depois de sua estreia na direção no irregular Feliz Natal (2008). Nachtergaele e Mello são atores de perfis distintos: Selton foi ator mirim de televisão e teatro, enquanto Nachtergaele foi formado essencialmente pelos palcos e pelo cinema, só aparecendo na televisão depois de consagrado nesses dois meios. Ambos têm, no entanto, a singularidade de serem atores cuja persona cinematográfica foi utilizada de maneira inteligente pelo meio televisivo e de serem atores capazes de negociar suas aparições nas ficções televisivas. Eles se encontram entre os atores mais relevantes da fase contemporânea do cinema brasileiro e podem abrir espaço para a construção de estrelas menos dependentes do meio televisivo e de atores-autores nos moldes do cinema americano. 


\section{Referências}

ALBERA, F. Albatros: des russes à Paris 1919-1929. Milan: Mazzota; Paris: Cinémathèque Française, 1995.

BENJAMIN, W. L'ouvre d'art à l'époque de sa reproductibilité technique. Paris: Ed. Allia, 2003.

DYER, R. Stars. Londres: British Film Institute, 1992.

KAZANSKI, B. "La nature du cinéma”. In: ALBERA, F. (Org.). Les formalistes russes et le cinema. Paris: Nathan, 1996.

McGILLIGAN, P. James Cagney: the actor as auteur. Londres: Tantivity, 1975.

. "L'acteur comme auteur: James Cagney, Ronald Reagan et Clint Eastwood". In: AMIEL, V. et al (Org.). L'acteur de cinéma: approches plurielles. Rennes: PUR, 2007.

MORIN, E. As estrelas: mitos e sedução no cinema. Rio de Janeiro: José Olympio, 1984.

MOULLET, L. La politique des acteurs. Paris: Editions de l'Etoile - Cahiers du Cinéma, 1993.

PANOFSKY, E. “Style et matériau au cinéma”. Revue d'Esthétique: cinéma: théorie, lectures. Paris: Klincksieck, 1978. 